\title{
MICROBIAL ECOLOGY
}

Microb Ecol (2002) 43:482

DOI: $10.1007 / \mathrm{s} 00248-002-0010-7$

(C) 2002 Springer-Verlag New York Inc.

\section{Erratum}

In H.F. von Canstein, Y. Li., A. Felske, and I. Wagner-Döbler, "Long-Term Stability of Mercury-Reducing Microbial Biofilm Communities Analyzed by 16S-23S rDNA Interspacer Region Polymorphism," Microb Ecol 42:624-634 (DOI: 10.1007/s00248-001-0028-6), the wrong Figure 1 appeared on page 627 due to a printer's error. We wish to apologize to the authors of the article, the readers, and the editors of the journal for this mistake.

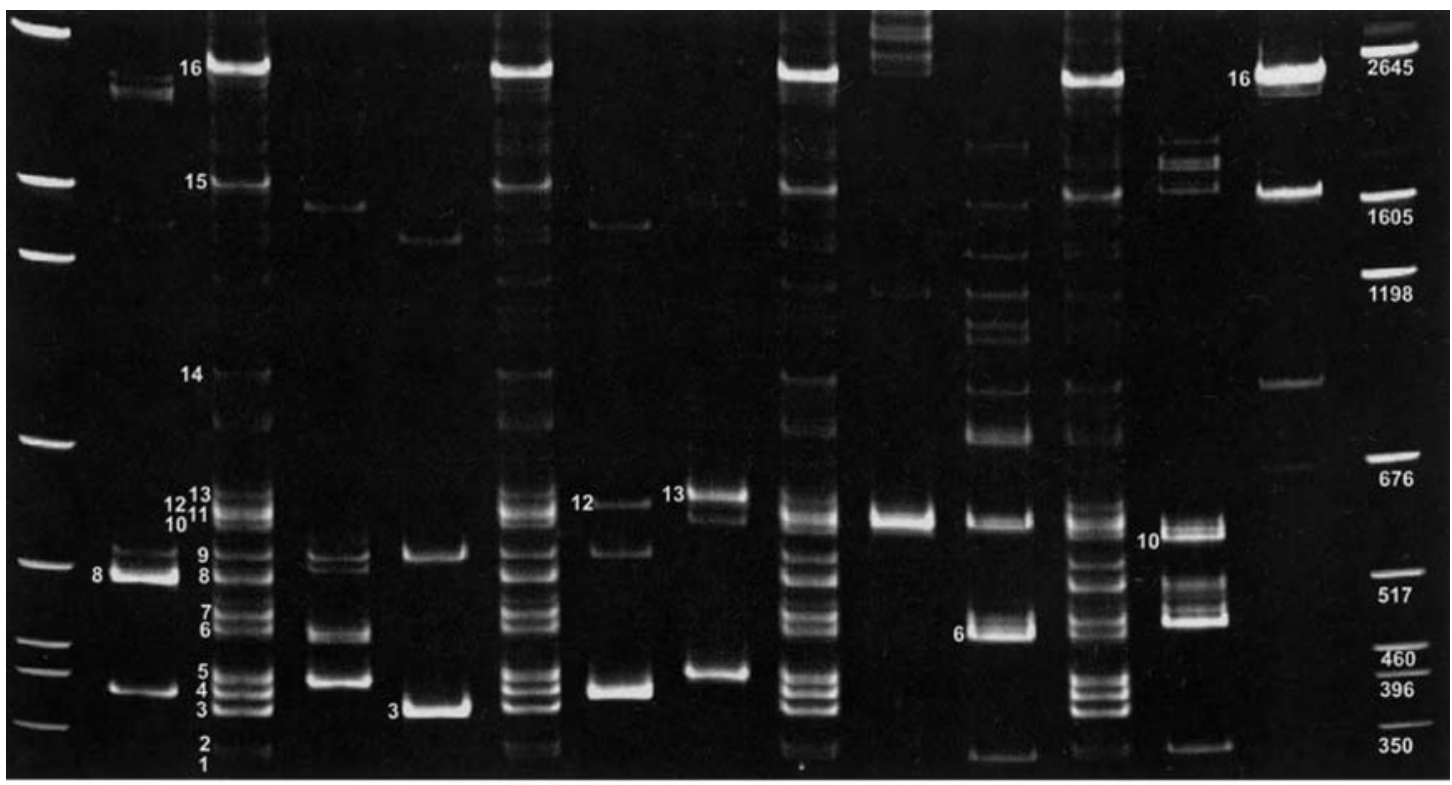

$\begin{aligned} & \text { size Spi } 3 \\ & \text { marker }\end{aligned}$
CM Elb 2 Spi 4 CM Kon 12 Spi 11 CM Elb 5 Spi 5 CM Tin 2 Spi $7 \begin{array}{r}\text { size } \\ \text { marker }\end{array}$

Fig. 1. ISR fingerprints of the 9 inoculum strains. The community marker (CM) consists of a mixture of the ISRs of the 9 inoculum strains amplified separately. The numbers at the fingerprint bands indicate the diagnostic bands and their position in the community marker. The numbers at the size marker bands indicate their size in base pairs. See Methods section for details. 